\title{
Reduction in high-frequency hearing loss following technical modifications to microvascular decompression for hemifacial spasm
}

\author{
Parthasarathy Thirumala, MD, Andrew M. Frederickson, MS, Jeffrey Balzer, PhD, \\ Donald Crammond, PhD, Miguel E. Habeych, MD, Yue-Fang Chang, PhD, and \\ Raymond F. Sekula Jr., MD \\ Department of Neurological Surgery, University of Pittsburgh Medical Center, Pittsburgh, Pennsylvania
}

\begin{abstract}
OBJECT Microvascular decompression is a safe and effective procedure to treat hemifacial spasm, but the operation poses some risk to the patient's hearing. While severe sensorineural hearing loss across all frequencies occurs at a low rate in experienced hands, a recent study suggests that as many as one-half of patients who undergo this procedure may experience ipsilateral high-frequency hearing loss (HFHL), and as many as one-quarter may experience contralateral HFHL. While it has been suggested that drill-related noise may account for this finding, this study was designed to examine the effect of a number of techniques designed to protect the vestibulocochlear nerve from operative manipulation on the incidence of HFHL.
\end{abstract}

METHODS Pure-tone audiometry was performed both preoperatively and postoperatively on 67 patients who underwent microvascular decompression for hemifacial spasm during the study period. A change of greater than $10 \mathrm{~dB}$ at either $4 \mathrm{kHz}$ or $8 \mathrm{kHz}$ was considered to be HFHL. Additionally, the authors analyzed intraoperative brainstem auditory evoked potentials from this patient cohort.

RESULTS The incidence of ipsilateral HFHL in this cohort was $7.4 \%$, while the incidence of contralateral HFHL was $4.5 \%$. One patient (1.5\%; also included in the HFHL group) experienced an ipsilateral nonserviceable hearing loss.

CONCLUSIONS The reduced incidence of HFHL in this study suggests that technical modifications including performing the procedure without the use of fixed retraction may greatly reduce, but not eliminate, the occurrence of HFHL following microvascular decompression for hemifacial spasm.

http://thejns.org/doi/abs/10.3171/2014.12.JNS141699

KEY WORDS hemifacial spasm; hearing loss; microvascular decompression; surgical technique

$\mathrm{M}$ ICROVASCULAR decompression (MVD) is a safe and efficacious procedure for the treatment of hemifacial spasm (HFS), a debilitating condition that reduces patients' quality of life. Severe sensorineural hearing loss (SNHL) across all frequencies is a known complication of the operation, with reported rates ranging from $1.4 \%$ to $20 \%{ }^{4,12,18-21,24}$ In addition to severe SNHL, however, a recent report has raised concern that as many as one-half of patients undergoing MVD for HFS may expe- rience high-frequency $(4-8 \mathrm{kHz})$ hearing loss. ${ }^{28}$ Although this type of hearing loss is not as obviously apparent upon clinical follow-up as severe SNHL, high-frequency hearing loss (HFHL) can profoundly reduce the quality of life of patients..$^{5,10}$ Although the prior report implicated noise from the high-speed surgical drill as the cause of HFHL following MVD, we conducted this study to examine the incidence of HFHL, with an emphasis on retractorless MVD for treatment of HFS.

ABBREVIATIONS BAEP = brainstem auditory evoked potential; HFHL = high-frequency hearing loss; HFS = hemifacial spasm; MVD = microvascular decompression; SNHL = sensorineural hearing loss; $\mathrm{SPL}=$ sound pressure level.

SUBMITTED July 31, 2014. ACCEPTED December 12, 2014.

INCLUDE WHEN CITING Published online July 10, 2015; DOI: 10.3171/2014.12.JNS141699.

DISCLOSURE The authors report no conflict of interest concerning the materials or methods used in this study or the findings specified in this paper. 


\section{Methods \\ Patient Selection}

With approval of the institutional review board, we retrospectively reviewed the medical records of all patients undergoing MVD for HFS, performed by the senior author (R.S.), at the University of Pittsburgh Medical Center between January 2012 and October 2013. All patients presenting with clinical features of HFS underwent preoperative electromyography testing for detection of an abnormal motor response or "lateral spread" elicited via stimulation of the zygomatic branch of the facial nerve and recorded from the mentalis muscle, confirming the diagnosis. ${ }^{22}$ At this time, patients also underwent preoperative brainstem auditory evoked potential (BAEP) testing. All patients underwent thin-slice T2-weighted MRI to evaluate vascular compression along the centrally myelinated portion of the facial nerve. ${ }^{11}$ Additionally, both preoperative and postoperative bilateral pure-tone audiometry was obtained for all patients. All medically stable patients, including patients of advanced age, those who had undergone prior MVD, or those with a history of facial botulinum toxin injections, were included in the study based on a positive abnormal motor response of the facial nerve and radiographically apparent neurovascular compression. ${ }^{11,23,24}$

\section{Operative Technique}

In all patients, MVD of the facial nerve was performed using techniques described in previous studies, ${ }^{14,17}$ as well as recent modifications designed to minimize fixed cerebellar retraction, which are detailed below. A self-retaining retractor was never used during any portion of the procedure. Strict management of fluids was initiated in preoperative holding, with the administration of intravenous fluids limited to only that amount necessary to maintain a normotensive state prior to dural opening (i.e., usually less than $500 \mathrm{ml}$ ). A modification of the physiological dose of mannitol $(0.25 \mathrm{~g} / \mathrm{kg})$, based on experience, was given 30 minutes prior to the start of the procedure, as well as an $8-\mathrm{mg}$ dose of dexamethasone. ${ }^{13}$ Initial intraoperative BAEPs were recorded prior to patient positioning. Patients were turned in the lateral decubitus position. ${ }^{14}$ Operative modifications included the use of a small retromastoid craniectomy measuring approximately $1.5 \mathrm{~cm} \times 2 \mathrm{~cm}$, created with an electric drill (Midas; Stryker). In addition, the neurosurgeon and neurophysiologist used agreed-upon "warning criteria" of the BAEPs to manage the flow and alter the mechanics of the operation, as described in detail in the section below. After exposing the facial nerve from the pontomedullary sulcus to its root detachment point, MVD was performed along the centrally myelinated portion of the facial nerve, with microscopic or endoscopic visualization in all patients. Finally, following a watertight closure, cement cranioplasty was performed. ${ }^{9}$

\section{Brainstem Auditory Evoked Potentials}

Real-time continuous BAEPs were recorded from all patients undergoing MVD for HFS. The ear ipsilateral to the MVD was stimulated using alternating rarefaction and condensation clicks with at least an $85-\mathrm{dB}$ sound pressure level (SPL) intensity. The contralateral ear was stimulated with a white noise of 65-dB SPL and responses recorded at baseline and at various times during the procedure. Clicks were delivered at a $17.5-\mathrm{Hz}$ frequency, with an observation interval of $12 \mathrm{msec}$, and each average was calculated from the results of 512 trials. Recording electrodes were positioned as follows: Channel 1, vertex to left ear mastoid; Channel 2, vertex to right mastoid; and Channel 3, vertex to C-2. The amplifier band pass was $100-1000 \mathrm{~Hz}$ for all channels. Baseline responses were obtained after anesthesia induction and patient positioning.

\section{Alarm Criteria}

To prevent inadvertent auditory nerve injury during retractorless surgery, we modified the traditionally accepted alarm criteria for BAEP changes. Traditionally, persistent decreases in amplitude greater than $50 \%$ of Wave $\mathrm{V}$ and persistent absolute latency increase of the peak of Wave $\mathrm{V}$, which equals or exceeds $0.5 \mathrm{msec}$, were considered significant. ${ }^{27}$ We modified the criteria so there was constant and frequent communication with the surgical team regarding the changes. The surgeon was specifically informed when the latency changes exceeded more than $0.25 \mathrm{msec}$ and if there was any change in amplitude. "Persistent changes" represent differences in amplitude or latency for 2 or more consecutive trials to reduce the effect of technical issues such as noise.

\section{Analysis of Neurophysiological Parameters}

We analyzed the amplitude and latency of Wave $\mathrm{V}$ and the interpeak latencies of Waves $I-V$, as described in a previous study. ${ }^{28}$ Analysis was performed at various stages during the surgery: 1) baseline, after intubation and positioning of the patient; 2) dura open, the epoch when the opening of the dura mater was documented; 3 ) change max, the maximum change in latency or amplitude recorded compared with average baseline waveform, including epochs when the responses were completely lost; and 4) on skin, the last epoch recorded.

\section{Audiometry}

Pure-tone audiometry was performed as described by Ying et al..$^{28}$ Preoperative audiometry was performed between 1 and 142 days (mean 9.2 days, median 1 day). Postoperative audiometry was performed between 1 and 16 days (mean 2.1 days, median 1 day). HFHL was defined as an increase of at least $15 \mathrm{~dB}$ in the hearing threshold at either $4000 \mathrm{~Hz}$ or $8000 \mathrm{~Hz}$. Nonserviceable hearing loss was defined by change in pure-tone audiometry of greater than $50 \mathrm{~dB}$ and speech discrimination scores of less than $50 \%$, by the American Academy of Otolaryngology-Head and Neck Surgery classification system. ${ }^{28}$

\section{Statistical Analysis}

Data were presented as mean \pm standard deviation as well as median for continuous variables and proportion for categorical variables. The differences between ipsilateral and contralateral audiogram thresholds were assessed by Wilcoxon signed-rank tests because of the skewness of the data. The analyses were carried out by SAS version 9.3 (SAS Institute Inc.). 
TABLE 1. Patient demographics

\begin{tabular}{lccccc}
\hline & \multicolumn{2}{c}{ Ipsilat } & & \multicolumn{2}{c}{ Contralat } \\
\cline { 2 - 3 } \cline { 6 - 6 } Characteristic & $\begin{array}{c}\text { HFHL } \\
(n=5)\end{array}$ & $\begin{array}{c}\text { NHFHL } \\
(n=62)\end{array}$ & & $\begin{array}{c}\text { HFHL } \\
(n=3)\end{array}$ & $\begin{array}{c}\text { NHFHL } \\
(n=64)\end{array}$ \\
\hline M/F ratio & $2 / 3$ & $18 / 44$ & & $1 / 2$ & $19 / 45$ \\
\hline Age (yrs) & $54.2 \pm 16.6$ & $54.4 \pm 12.5$ & & $53.4 \pm 14.1$ & $52.5 \pm 12.7$ \\
\hline Side (It/rt) & $3 / 2$ & $36 / 26$ & & $1 / 2$ & $38 / 26$ \\
\hline
\end{tabular}

\section{Results}

Preoperative and postoperative audiograms were available for 67 of 85 patients who underwent MVD during the study period. Of these 67 patients, 5 patients $(7.4 \%)$ had HFHL on the ipsilateral side and 3 patients $(4.5 \%)$ had HFHL on the contralateral side. Two patients $(3.0 \%)$ had bilateral HFHL following the operation and were included in both the ipsilateral and contralateral groups (Tables 1 and 2).

The mean pure-tone thresholds at each frequency are compared before and after the operation for both the ipsilateral and contralateral side in Table 3 and Fig. 1. Eleven (16.4\%) of 67 patients had undergone a previous ipsilateral MVD for HFS, while the remainder were undergoing their first operative procedure for this condition. Mean pure-tone thresholds for both the ipsilateral and contralateral sides are presented for patients undergoing first-time MVD in Table 4 and repeated MVD in Table 5.

No patient experienced a contralateral nonserviceable hearing loss and 1 patient $(1.5 \%)$ experienced an ipsilateral nonserviceable hearing loss. Since this patient had hearing loss across all frequencies including $4 \mathrm{kHz}$ and $8 \mathrm{kHz}$, she was also counted among those with ipsilateral HFHL. None of the 11 patients in this series who had previously undergone an ipsilateral MVD for HFS experienced HFHL or nonserviceable hearing loss.

No significant change in the amplitude or latency of Wave V of BAEPs was noted in patients with and without HFHL. Similarly, the interpeak latencies of Waves I-V between patients with and without HFHL was not significantly different (Table 6).

\section{Discussion}

In the present study, the incidence of HFHL was $7.4 \%$ and $4.5 \%$ ipsilateral and contralateral to the side of surgery, respectively. We were unable to detect a significant difference in the incidence of HFHL between the 2 sides $(\mathrm{p}=0.72)$. Additionally, no difference in HFHL was noted following first-time or repeated MVD. A prior study, conducted by the same neurophysiological monitoring team but a different neurosurgeon, at our institution included postoperative audiometry in every patient to detect HFHL ${ }^{28}$ In this study, the incidence of HFHL following MVD for HFS was found to be $50 \%$ and $25 \%$ on the ipsilateral and contralateral sides, respectively. ${ }^{28}$ The authors hypothesized that drill-induced noise and transient loss of CSF during surgery may impair hearing in the highfrequency ranges on both the ipsilateral and contralateral sides. Since both the previous and present studies used identical criteria in defining HFHL, the lower prevalence of HFHL in the current study may be due to a practice paradigm shift instituted at our institution by a new director of the Center for Cranial Nerve Disorders (R.S.), designed to minimize iatrogenic damage from the manipulation of neural tissue during the surgical procedure. This includes avoidance of fixed brain retraction, consistent use of alarm criteria of the BAEPs, and the optimization of neuroanesthesia delivery.

\section{Retractorless Surgery}

In recent years, some neurosurgeons have attempted to reduce the use of fixed retraction in supratentorial and infratentorial operations. The main goals of this trend have been to reduce the incidence of iatrogenic microtrauma and ischemia within the brain parenchyma. Techniques such as optimal patient positioning for gravity retraction, dynamic retraction, and flexible microsurgical instrumentation have all been used to reduce or eliminate the use of standard retractors., ${ }^{3,26}$ During MVD for HFS, fixed cerebellar retraction has historically been used to expose the cranial nerves..$^{15,17,25}$ When performing the operations in the 2008 study, the previous cranial nerve neurosurgical team at our institution routinely used both fixed and dynamic cerebellar retraction. ${ }^{28}$ While this offers the advantage of providing excellent exposure of the facial nerve, fixed retraction comes at several costs. Albin et al. have shown that excessive brain retraction may adversely affect cerebral perfusion pressure and somatosensory evoked potentials with resultant brain injury. ${ }^{1,2,16}$ Additionally, this type of manipulation may also lead to operative manipulation (e.g., stretching) of the vestibulocochlear nerve, leading to iatrogenic injury and subsequent hearing loss and balance issues. ${ }^{16}$ Accumulating experience and evidence

TABLE 2. Hearing loss following MVD for HFS

\begin{tabular}{|c|c|c|c|c|c|c|}
\hline \multirow[b]{2}{*}{$\begin{array}{c}\text { Audiometric } \\
\text { Frequency }(\mathrm{kHz})\end{array}$} & \multicolumn{3}{|c|}{ Ipsilat } & \multicolumn{3}{|c|}{ Contralat } \\
\hline & $\begin{array}{l}\text { Hearing Loss } \\
\text { (no.) }\end{array}$ & $\begin{array}{l}\text { No Hearing } \\
\text { Loss (no.) }\end{array}$ & $\begin{array}{l}\text { Hearing Loss } \\
(\%)\end{array}$ & $\begin{array}{l}\text { Hearing Loss } \\
\text { (no.) }\end{array}$ & $\begin{array}{l}\text { No Hearing } \\
\text { Loss (no.) }\end{array}$ & $\begin{array}{c}\text { Hearing Loss } \\
(\%)\end{array}$ \\
\hline $0.25^{*}$ & 9 & 58 & 13.4 & 3 & 64 & 4.5 \\
\hline $0.5-2$ & 9 & 58 & 13.4 & 4 & 63 & 6.0 \\
\hline 4 & 4 & 63 & 6.0 & 3 & 64 & 4.5 \\
\hline 8 & 3 & 64 & 4.5 & 1 & 66 & 1.5 \\
\hline 4 \&/or 8 & 5 & 62 & 7.4 & 3 & 64 & 4.5 \\
\hline
\end{tabular}

* $250 \mathrm{~Hz}$ was not included in the postoperative audiometric testing of 3 patients. 
TABLE 3. Mean pure-tone thresholds*

\begin{tabular}{|c|c|c|c|c|c|c|}
\hline \multirow{2}{*}{$\begin{array}{c}\text { Audiometric } \\
\text { Frequency }(\mathrm{kHz})\end{array}$} & \multicolumn{2}{|c|}{ Preop, dB } & \multicolumn{2}{|c|}{ Postop, dB } & \multicolumn{2}{|c|}{$p$ Value } \\
\hline & Ipsilat & Contralat & Ipsilat & Contralat & Ipsilat Difference & Contralat Difference \\
\hline $0.25 \dagger$ & $15.2 \pm 8.2$ & $14.5 \pm 9.93$ & $19.1 \pm 13.2$ & $17.4 \pm 10.7$ & 0.0004 & 0.0001 \\
\hline $0.5-2$ & $17.1 \pm 11.5$ & $16.9 \pm 11.6$ & $20.1 \pm 16.0$ & $18.6 \pm 12.7$ & 0.0002 & 0.0002 \\
\hline 4 & $22.5 \pm 17.0$ & $22.3 \pm 18.0$ & $25.1 \pm 20.3$ & $23.4 \pm 19.2$ & 0.064 & 0.118 \\
\hline 8 & $24.0 \pm 21.3$ & $24.3 \pm 21.9$ & $25.2 \pm 21.0$ & $25.1 \pm 21.4$ & 0.225 & 0.549 \\
\hline
\end{tabular}

* Values are presented as the mean \pm SD unless otherwise indicated.

$\dagger 250 \mathrm{~Hz}$ was not included in the postoperative audiometric testing of 3 patients.

suggest that if the ultimate goal of an operation (e.g., clipping of an aneurysm, resection of a vascular malformation or tumor) can be achieved without a retractor, a retractor should not be used in brain surgery.

\section{Intraoperative Neuromonitoring and Alarm Criteria}

Evidence suggests that the use of BAEP monitoring during MVD reduces the incidence of hearing loss, though a minority of surgeons disagree. ${ }^{4,7,20}$ In our series, we did not find any significant difference in latency and amplitude of Wave $\mathrm{V}$ of BAEPs during MVD in patients with and without HFHL. As part of the institutional paradigm shift, we used alarm criteria developed by the senior author (R.S.) and based on both experience and modifications to the guidelines set forth by Polo et al. ${ }^{20}$ When the latency of Peak V increased by greater than $0.5 \mathrm{msec}$ from baseline, all instruments were removed from the wound and the operation was stopped until the latency returned to baseline. It is not uncommon for several, short surgical pauses (i.e., lasting minutes) to take place during these procedures. These pauses are important regardless of whether fixed retraction is used, because the shaft of a surgical instrument can dynamically retract and lead to changes in evoked potentials, as the focus of the surgical team is on the tip of the instruments and the deep vascular and neural anatomy. If the surgical instruments are not removed and the surgery continues, even in the face of no fixed retraction and a mild to modest delay in signals, an increase in morbidity may occur. This is in contrast to the previous surgical team at our institution, which continued to operate if there was a latency of Peak V greater than 0.5 msec and only removed surgical instruments and ceased the operation when there was a diminution in the amplitude of Peak V. We feel that the important aspect of implementing successful alarm criteria is in the communication between the surgical and neurophysiological teams. This communication needs to be open and dynamic, and occur in real time. Any hesitation in reporting of changes can lead to delay in surgical intervention and iatrogenic injury. This aspect of intraoperative monitoring in MVD procedures cannot be stressed enough.

\section{Optimal Neuroanesthesia Care}

Optimal neuroanesthesia delivery is an important com-

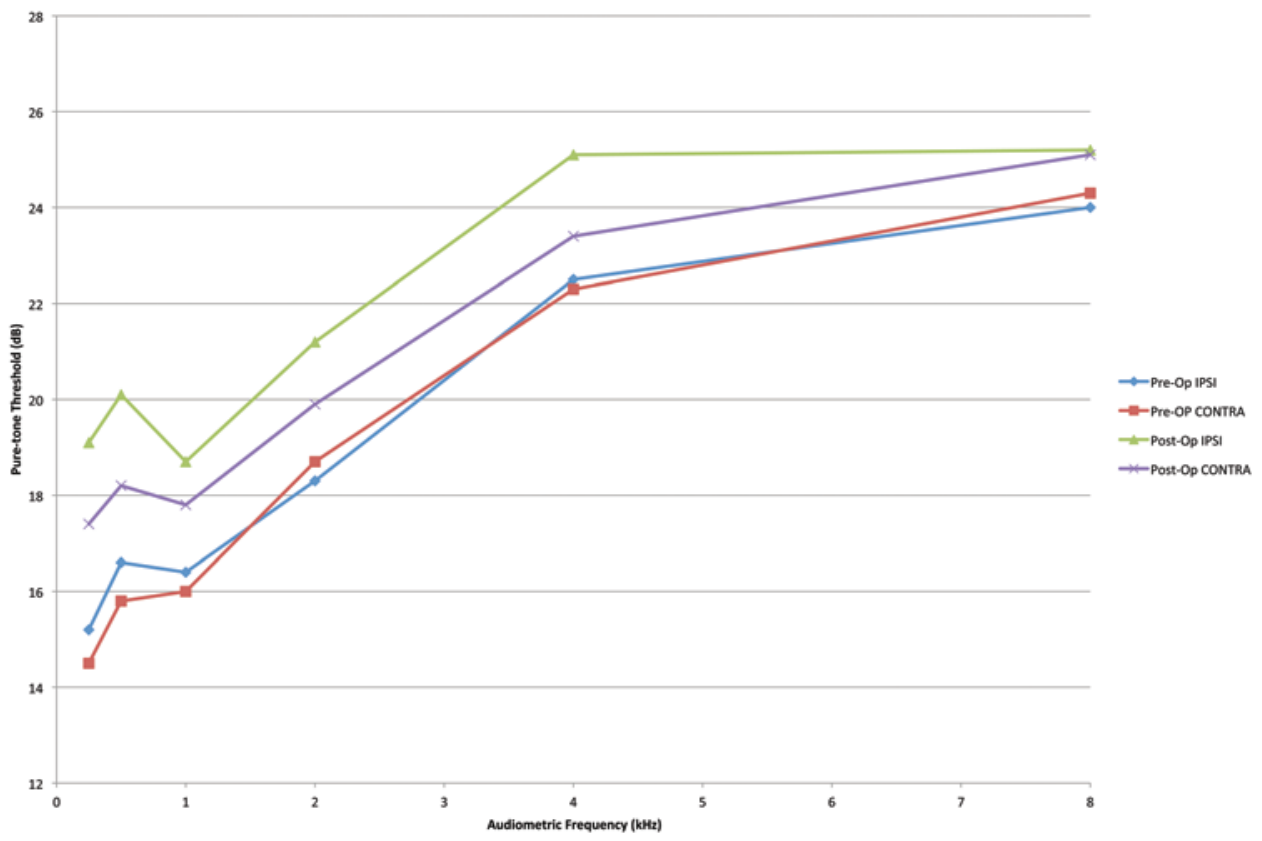

FIG. 1. Mean pure-tone thresholds. This figure shows the mean pure-tone threshold at each frequency across all patients on both the ipsilateral (IPSI) and contralateral (CONTRA) sides. While the hearing threshold increased postoperatively on both sides, the increase was greater on the ipsilateral side. Figure is available in color online only. 
TABLE 4. Mean pure-tone thresholds in 56 patients undergoing first-time MVD only

\begin{tabular}{cccccc}
\hline \multirow{2}{*}{$\begin{array}{c}\text { Audiometric Frequency } \\
(\mathrm{kHz})\end{array}$} & \multicolumn{2}{c}{ Preop $(\mathrm{dB})$} & & \multicolumn{2}{c}{ Postop $(\mathrm{dB})$} \\
\cline { 2 - 3 } \cline { 6 - 6 } & Ipsilat & Contralat & & Ipsilat & Contralat \\
\hline 0.25 & 15.3 & 14.7 & & 19.5 & 17.8 \\
\hline $0.5-2$ & 17.5 & 17.3 & & 20.5 & 19.2 \\
\hline 4 & 23.3 & 23.0 & & 21.0 & 24.5 \\
\hline 8 & 24.8 & 25.6 & & 21.7 & 26.4 \\
\hline
\end{tabular}

ponent of any neurosurgical procedure. During MVD, optimal care begins with management of intravenous fluids. In our practice, the administration of intravenous fluids is limited to an arbitrary target of less than $500 \mathrm{ml}$ prior to opening of the dura, in an effort to avoid iatrogenic intracranial hypertension. A modified physiological dose of mannitol is administered 30-60 minutes prior to skin incision. With this low dose, recognizable disturbances in electrolyte concentrations, renal function, and coagulation have not been noted. Hemodynamic stability is maintained with a combination of inhalation and intravenous anesthesia. Optimal patient positioning facilitates gravityenhanced relaxation of the cerebellum and appropriate venous return. Blood loss is kept to a minimum (i.e., usually less than $25 \mathrm{ml}$ per procedure). No patient in this series required a blood transfusion.

\section{Drill-Induced SNHL}

While it is clear that operative manipulation of the vestibulocochlear nerve can result in SNHL, drill-generated noise created during craniotomy has also been suggested as a cause for HFHL. ${ }^{8,28}$ Drill-generated noise may damage hearing by either mechanical stretch of the inner-ear structures or through metabolic changes in the cochlear cells. ${ }^{6}$ Farzanegan et al. showed that patients undergoing supratentorial craniotomy for brain tumor resection developed SNHL that was restricted to the higher frequencies. ${ }^{8}$ Despite taking precautions to reduce operative trauma to the vestibulocochlear nerve, using a retractorless technique, a small number of patients in this study did have HFHL following MVD. While some of the HFHL observed may be due to operative manipulation that can never be truly avoided, drill-induced acoustic damage remains a possible etiology in these patients.

\section{Study Limitations}

In addition to the small sample size, a limitation of this study is that although every patient who underwent MVD

TABLE 5. Mean pure-tone thresholds in 11 patients undergoing repeated MVD only

\begin{tabular}{cccccc}
\hline \multirow{2}{*}{$\begin{array}{c}\text { Audiometric Frequency } \\
(\mathrm{kHz})\end{array}$} & \multicolumn{2}{c}{ Preop $(\mathrm{dB})$} & & \multicolumn{2}{c}{ Postop $(\mathrm{dB})$} \\
\cline { 2 - 3 } \cline { 5 - 6 } & Ipsilat & Contralat & & Ipsilat & Contralat \\
\hline 0.25 & 14.3 & 12.9 & & 14.2 & 14.2 \\
\hline $0.5-2$ & 12.1 & 13.3 & & 13.8 & 13.3 \\
\hline 4 & 12.9 & 16.4 & & 12.9 & 14.3 \\
\hline 8 & 14.3 & 13.6 & & 11.7 & 14.3 \\
\hline
\end{tabular}

TABLE 6. Intraoperative neuromonitoring results

\begin{tabular}{lcr}
\hline \multicolumn{1}{c}{ Variable } & HFHL & No HFHL \\
\hline Latency wave $(\mathrm{msec})$ & & \\
\hline Baseline & $6.63 \pm 0.31$ & $6.41 \pm 0.33$ \\
\hline Change max & $7.47 \pm 0.31$ & $7.22 \pm 0.44$ \\
\hline Change max vs baseline & 112.59 & $112.82 \pm 5.13$ \\
\hline Amplitude wave $(\mu \mathrm{V})$ & & \\
\hline Baseline & $0.37 \pm 0.06$ & $0.37 \pm 0.11$ \\
\hline Change max & $0.37 \pm 0.23$ & $0.32 \pm 0.10$ \\
\hline Change max vs baseline & $94.44 \pm 52.92$ & $91.93 \pm 28.47$ \\
\hline IPL waves I-V (msec) & & \\
\hline Baseline & $4.47 \pm 0.06$ & $4.47 \pm 0.36$ \\
\hline Change max & $4.87 \pm 0.15$ & $5.04 \pm 0.47$ \\
\hline Change max vs baseline & $108.99 \pm 4.60$ & $113.08 \pm 11.20$ \\
\hline
\end{tabular}

$\mathrm{IPL}=$ interpeak latency.

for HFS during the study period was asked to undergo both a preoperative and postoperative audiogram, data from both hearing tests were only available for 67 of 85 consecutive patients (78.8\%), which compares favorably to the previous report from our center in which both preoperative and postoperative hearing data were available for 94 of $152(61.8 \%)$ of patients. ${ }^{28}$ This could actually lead to overreporting of HFHL prevalence if patients who did not feel that they experienced a postoperative change in hearing status did not have sufficient motivation to obtain a postoperative hearing test. Additionally, a difference in the median time to postoperative audiometric follow-up limits the ability to compare incidences of HFHL between the present study (median time to audiogram 2 days) and the previous study (median time to audiogram 7 days). ${ }^{28}$ Finally, this study is limited by the lack of available longterm audiometric data on the patients with HFHL. Whether this type of hearing deficit changes over time is not known. To answer this question, we have begun to collect long-term audiometric data on all patients with HFHL.

\section{Conclusions}

SNHL after MVD is an often underdiagnosed condition. The magnitude of the problem is unknown due to ambiguous or differing measures among studies of what constitutes SNHL. This debilitating complication is often mitigated by the use of BAEPs. Performing the procedure without the use of fixed retraction may help reduce both HFHL and SNHL. Drill-related noise and/or CSF diversion, however, may still contribute to postoperative HFHL and SNHL, as evidenced by contralateral hearing loss that was observed in this and our previous study. Long-term studies and longitudinal audiogram information from other patients will contribute to a greater understanding of this problem.

\section{References}

1. Albin MS, Bunegin L, Bennett MH, Dujovny M, Jannetta PJ: Clinical and experimental brain retraction pressure monitoring. Acta Neurol Scand Suppl 64:522-523, 1977

2. Albin MS, Bunegin L, Dujovny M, Bennett MH, Jannetta PJ, 
Wisotzkey HM: Brain retraction pressure during intracranial procedures. Surg Forum 26:499-500, 1975

3. Andrews RJ, Bringas JR: A review of brain retraction and recommendations for minimizing intraoperative brain injury. Neurosurgery 33:1052-1064, 1993

4. Barker FG II, Jannetta PJ, Bissonette DJ, Shields PT, Larkins MV, Jho HD: Microvascular decompression for hemifacial spasm. J Neurosurg 82:201-210, 1995

5. Chia EM, Wang JJ, Rochtchina E, Cumming RR, Newall P, Mitchell P: Hearing impairment and health-related quality of life: the Blue Mountains Hearing Study. Ear Hear 28:187195,2007

6. Clark WW, Bohne BA: Effects of noise on hearing. JAMA 281:1658-1659, 1999

7. Dannenbaum M, Lega BC, Suki D, Harper RL, Yoshor D: Microvascular decompression for hemifacial spasm: longterm results from 114 operations performed without neurophysiological monitoring. J Neurosurg 109:410-415, 2008

8. Farzanegan G, Ghasemi M, Panahi F, Raza M, Alghasi M: Does drill-induced noise have an impact on sensorineural hearing during craniotomy procedure? Br J Neurosurg 24:40-45, 2010

9. Frederickson AM, Sekula RF Jr: The utility of calcium phosphate cement in cranioplasty following retromastoid craniectomy for cranial neuralgias. Br J Neurosurg 27:808-811, 2013

10. Helvik AS, Krokstad S, Tambs K: Hearing loss and risk of early retirement. The HUNT study. Eur J Public Health 23:617-622, 2013

11. Hughes MA, Branstetter BF, Frederickson AM, Oskin JE, Yankevich U, Sekula RF: Imaging hemifacial spasm. Neurographics 5:2-8, 2015

12. Huh R, Han IB, Moon JY, Chang JW, Chung SS: Microvascular decompression for hemifacial spasm: analyses of operative complications in 1582 consecutive patients. Surg Neurol 69:153-157, 2008

13. Jaffe RA, Schmiesing CA, Golianu B (eds): Anesthesiologist's Manual of Surgical Procedures, ed 5. Philadelphia: Wolters Kluwer Health, 2014

14. Jannetta PJ (ed): Trigeminal Neuralgia. New York: Oxford University Press, 2011

15. Kong DS, Park K: Hemifacial spasm: a neurosurgical perspective. J Korean Neurosurg Soc 42:355-362, 2007

16. Laha RK, Dujovny M, Rao S, Barrionuevo PJ, Bunegin L, Hellstrom HR, et al: Cerebellar retraction: significance and sequelae. Surg Neurol 12:209-215, 1979

17. McLaughlin MR, Jannetta PJ, Clyde BL, Subach BR, Comey $\mathrm{CH}$, Resnick DK: Microvascular decompression of cranial nerves: lessons learned after 4400 operations. J Neurosurg 90:1-8, 1999

18. Moffat DA, Durvasula VS, Stevens King A, De R, Hardy DG: Outcome following retrosigmoid microvascular decompression of the facial nerve for hemifacial spasm. J Laryngol Otol 119:779-783, 2005

19. Park K, Hong SH, Hong SD, Cho YS, Chung WH, Ryu NG: Patterns of hearing loss after microvascular decompression for hemifacial spasm. J Neurol Neurosurg Psychiatry 80:1165-1167, 2009
20. Polo G, Fischer C, Sindou MP, Marneffe V: Brainstem auditory evoked potential monitoring during microvascular decompression for hemifacial spasm: intraoperative brainstem auditory evoked potential changes and warning values to prevent hearing loss-prospective study in a consecutive series of 84 patients. Neurosurgery 54:97-106, 2004

21. Samii M, Günther T, Iaconetta G, Muehling M, Vorkapic P, Samii A: Microvascular decompression to treat hemifacial spasm: long-term results for a consecutive series of 143 patients. Neurosurgery 50:712-719, 2002

22. Sekula RF Jr, Bhatia S, Frederickson AM, Jannetta PJ, Quigley MR, Small GA, et al: Utility of intraoperative electromyography in microvascular decompression for hemifacial spasm: a meta-analysis. Neurosurg Focus 27(4):E10, 2009

23. Sekula RF Jr, Frederickson AM, Arnone GD, Quigley MR, Hallett M: Microvascular decompression for hemifacial spasm in patients $>65$ years of age: an analysis of outcomes and complications. Muscle Nerve 48:770-776, 2013

24. Sekula RF Jr, Frederickson AM, Branstetter BF IV, Oskin JE, Stevens DR, Zwagerman NT, et al: Thin-slice T2 MRI imaging predicts vascular pathology in hemifacial spasm: a case-control study. Mov Disord 29:1299-1303, 201425. Sindou MP: Microvascular decompression for primary hemifacial spasm. Importance of intraoperative neurophysiological monitoring. Acta Neurochir (Wien) 147:1019-1026, 2005

26. Spetzler RF, Sanai N: The quiet revolution: retractorless surgery for complex vascular and skull base lesions. J Neurosurg 116:291-300, 2012

27. Thirumala PD, Krishnaiah B, Crammond DJ, Habeych ME, Balzer JR: Analysis of wave III of brain stem auditory evoked potential waveforms during microvascular decompression of cranial nerve VII for hemifacial spasm. J Clin Neurophysiol 31:127-132, 2014

28. Ying T, Thirumala P, Shah A, Nikonow T, Wichman K, Holmes M, et al: Incidence of high-frequency hearing loss after microvascular decompression for hemifacial spasm. J Neurosurg 118:719-724, 2013

\section{Author Contributions}

Conception and design: Sekula, Thirumala, Crammond, Habeych. Acquisition of data: Thirumala, Frederickson. Analysis and interpretation of data: Sekula, Frederickson. Drafting the article: Sekula, Frederickson. Critically revising the article: Sekula, Thirumala, Frederickson, Balzer. Reviewed submitted version of manuscript: Sekula, Thirumala, Frederickson, Balzer, Crammond, Habeych. Approved the final version of the manuscript on behalf of all authors: Sekula. Statistical analysis: Thirumala, Chang. Administrative/technical/material support: Frederickson. Study supervision: Thirumala.

\section{Correspondence}

Raymond F. Sekula Jr., Department of Neurological Surgery, University of Pittsburgh Medical Center, 200 Lothrop St., Ste. B-400, Pittsburgh, PA 15213. email: sekularf@upmc.edu. 